\title{
Severe tricuspid regurgitation caused by pacemaker lead interference
}

\author{
Ciężka niedomykalność zastawki trójdzielnej spowodowana \\ interferencją z elektrodą rozrusznika serca
}

\author{
Anna Rydlewska ${ }^{1}$, Barbara Małecka ${ }^{1,2}$, Andrzej Ząbek ${ }^{1}$, Małgorzata Hardzina ${ }^{1}$, Jacek Lelakowski ${ }^{1,2}$ \\ ${ }^{1}$ Department of Electrocardiology, John Paul II Hospital in Krakow, Poland \\ ${ }^{2}$ Institute of Cardiology, Jagiellonian University Medical College, John Paul II Hospital in Krakow, Poland
}

A 19-year-old patient was admitted to the hospital for routine pacemaker (PM) reimplantation due to battery depletion. A single chamber (VVI) transvenous PM had been implanted when the patient was 11 years old, following previous epicardial stimulation due to congenital atrio-ventricular complete heart block. On admission, the patient was asymptomatic. Electrical parameters of the PM were within normal range. Transthoracic echocardiography (TTE) however revealed severe tricuspid regurgitation (TR) caused by lead interference with the septal platelet of the tricuspid valve (Fig. 1). Chest X-ray showed that the lead was stretched (Fig. 2). Due to significant interference between the lead and the tricuspid valve, the patient was qualified to transvenous lead extraction with simultaneous dual chamber PM implantation (Fig. 3). A new PM with a lead length appropriate to the patient's dimensions was implanted. In a three-month follow up after the procedure, a significant reduction of TR was observed (Fig. 4). Benign TR is a frequently described phenomenon after PM implantation. However, severe TR is relatively rare. Among possible causes of the regurgitation, several mechanisms have been described: platelet perforation, lead entanglement in valve structures, lead impingement of the platelets, and fibrotic adhesions between platelets and the lead. Possible risk factors are: older age, diastolic heart failure, use of cardioverter-defibrillator leads, and apical stimulation. In the described case, apical PM stimulation led to severe TR. The most probable explanation was tricuspid valve platelet 'support' by the lead, which as the patient grew became rectified and began to interfere with the valve. This hypothesis is further supported by the fact that after PM replacement, the regurgitation subsided. Our patient was asymptomatic. Severe regurgitation when diagnosed too late, after tricuspid annulus has extended, may lead to irreversible changes, and lead extraction alone may not resolve the problem. TR when diagnosed and treated early allows cardiosurgical intervention to be avoided along with possible complications, such as heart failure.

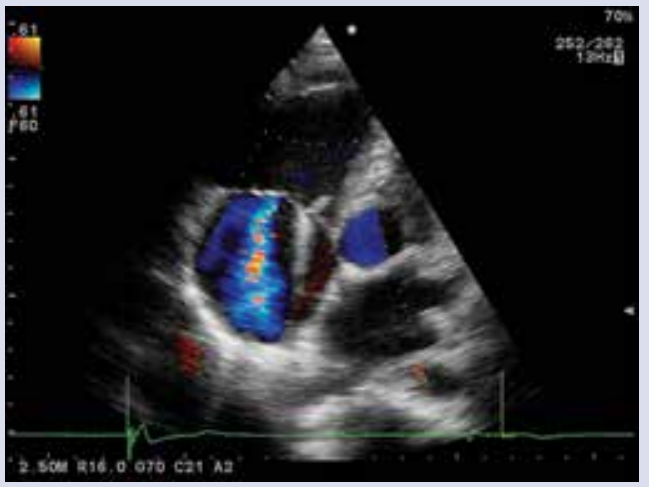

Figure 1. TTE — severe tricuspid regurgitation with lead 'supporting' septal platelet

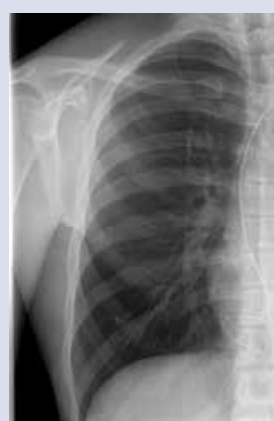

Figure 2. Chest X-ray — 'rectified' pacemaker lead

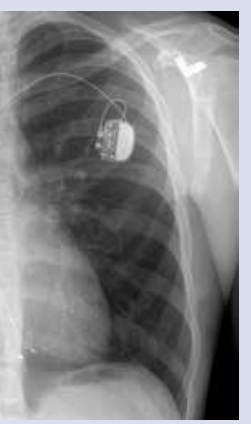

Figure 3. Chest $\mathrm{X}$-ray after lead extraction and dual chamber pacemaker implantation

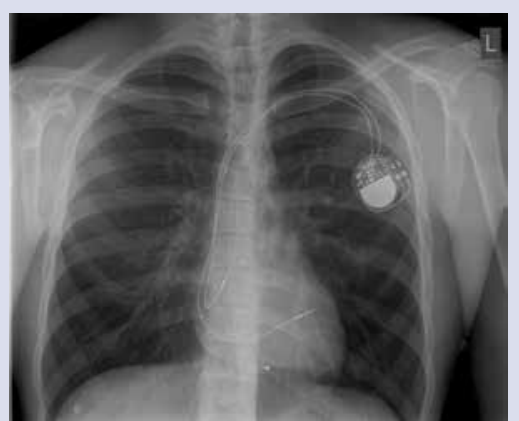

Figure 4. TTE — significant tricuspid regurgitation reduction

Address for correspondence:

Anna Rydlewska, MD, Department of Electrocardiology, John Paul II Hospital in Krakow, Jagiellonian University, School of Medicine, ul. Prądnicka 80, 30-611 Kraków, Poland, e-mail: annarydlewska@op.pl

Conflict of interest: Anna Rydlewska — faculty fee for Medtronic, Poland; Barbara Małecka — sponsorship of conferences participation by Medtronic and Biotronik 